\title{
EL CONTROL CIENTIFICO DEL FRAUDE ALIMENTARIO: DEL INSTITUTO DE HIGIENE AL LABORATORIO MUNICIPAL. CHILE, 1892-1902*
}

\author{
THE SCIENTIFIC CONTROL OF FOOD FRAUD: FROM THE \\ INSTITUTE OF HYGIENE TO THE MUNICIPAL LABORATORY. \\ CHILE, 1892-1902
}

\section{MARÍA JOSÉ CORREA GÓMEZ**}

RESUMEN: Hacia fines del siglo XIX se registró un aumento en el reconocimiento del fraude alimentario, que coincidió con el desarrollo agroindustrial y con un mayor control sanitario de los espacios urbanos a través de nuevas políticas de higiene. Este artículo introduce al estudio de la conformación de la estructura científica que se organizó para controlar dicho fraude. A través de fuentes institucionales, legales y judiciales explora el primer decenio de funcionamiento del Instituto de Higiene y el gradual surgimiento de una estructura fiscalizadora municipal asentada en el laboratorio, en los inspectores y en los químicos, que complementó la labor inicial del Instituto, principalmente en provincia. Esta estructura posicionó al laboratorio como primer espacio de fiscalización de los alimentos y como instancia de certificación del fraude en tribunales.

Palabras clave: Fraude alimentario, análisis, higiene, laboratorio municipal, justicia.

Aвstract: By the end of the nineteenth century the rise of food fraud overlapped with agro-industrial development and with a greater sanitary control of urban spaces trough new hygiene policies. This article presents the conformation of food fraud and the scientific structure organized for its management. It explores through governmental, legal and judicial sources, the first decade of the Institute of Hygiene and the arrival of a municipal mechanism of inspection based on the laboratory, inspectors, and chemists, which complemented the initial work of the Institute, especially in the provinces. This mechanism positioned the laboratory both, as a prior space of food inspection, and as a relevant instance of certification of food fraud in court.

Keywords: Food Fraud, Analysis, Hygiene, Municipal Laboratory; Justice.

Recibido: 28.12.2020. Aceptado: 23.08.2021.

\footnotetext{
* Este artículo se inscribe en el proyecto Fondecyt regular núm. 1200898 (2020/2024) "Los alimentos modernos y sus peligros: gestionar el riesgo y estandarizar la calidad. Chile urbano, 1854-1931”, del cual soy investigadora responsable. Agradezco al equipo que integra el proyecto y a los evaluadores de la revista por sus pertinentes y útiles sugerencias.

** Doctora en Historia. Académica del Departamento de Humanidades, Universidad Andrés Bello, Santiago, Chile. Correo electrónico: maria.correa@unab.cl. Orcid: https://orcid.org/0000-0002-4252-8538
} 
T AcIA Mediados DEL SIGLO XIX aumentó el interés por custodiar los Se vislumbraba el inicio de una producción manufacturera a mayor escala y la circulación de nuevos productos importados, así como una densificación de la vida urbana y, con ella, nuevas dinámicas de consumo. Esta atención derivó en un sistema cada vez más burocratizado de fiscalización, regido por criterios científicos, que se proyectaron en distintas instancias de la vida citadina y de su gobierno. Como resultado, numerosos alimentos y bebidas fueron considerados problemáticos y calificados como dañosos, bajo regulaciones que intentaban determinar composiciones y calificaciones. A su identidad peligrosa se agregó su criminalización, tras ser identificados como fraudulentos o adulterados, lo que llevó a su marginación del mercado, a través del decomiso y la desaparición. Sus productores y vendedores fueron castigados con multas, despojados de sus mercaderías y presentados como adulteradores, dentro de una industria alimentaria que se forjaba entre los aplausos y las sospechas.

Así sucedió hacia 1901 con un grupo de comerciantes de la ciudad de San Felipe, acusados de arriesgar la salud de sus vecinos con sus productos falseados. Luciano Rector fue amonestado varias veces por vender grasa mezclada con sebo y chicha aguada, al igual que Rosario Ríos, por ofrecer en su local comercial vino tinto fermentado y avinagrado, el que tuvo como único consumidor al río Aconcagua. Antonio Ramírez fue reprendido por vender Chacoli blanco con una mayor agregación de azúcar, caso similar al de Moisés Zamora, acusado de comercializar una chicha de uvas verdes y con exceso de agua (Archivo Judicial de San Felipe, Laboratorio Químico, 1901, C1112, P3; C770, P7; C794, P9; C770, P8; y C770, P9).

Luciano, Rosario, Antonio y Moisés integraban un mercado alimenticio en transformación. Sus acciones y experiencias se relacionaron con los cambios que enfrentaban los alimentos durante el desarrollo agroindustrial y el gradual crecimiento de la cultura urbana, así como con los desafíos que implicaba su producción y venta en un circuito cada vez más competitivo. La complejidad de la cadena productiva, el crecimiento de la tecnología y de la técnica, la circulación de productos desconocidos y la densificación del escenario comercial, profundizaron y al mismo tiempo crearon nuevas experiencias. El progreso trajo oportunidades, pero también peligros, que acompañaron y recortaron la gestión de los alimentos.

La modernidad inauguró un ciclo riesgoso, con efectos evidentes no solo durante el siglo XX, en tanto periodo de consolidación del progreso, sino durante gran parte del XIX, en contextos de modernización temprana 
y parcial (Vieira, 2016; Boudia y Jas, 2007). Sus peligros se manifestaron en el ámbito de los alimentos, en parte por el cambio en los procesos productivos, el surgimiento de nuevos productos y el incremento de la distancia entre la producción primaria y el consumo de los alimentos, entre "el campo y la mesa" (Rioux, 2018; Gutiérrez, B., 2018; Guillem-Llobat, 2009). Esto fue especialmente notorio durante el cambio de siglo cuando las preocupaciones estatales, médicas y legales, así como de productores y consumidores, se articularon con una institucionalidad higiénica en ciernes, que fue capaz de constatar los nuevos peligros que se adscribían a alimentos y bebidas (Degreef y Scholliers, 2019, pp. 5-6). La mirada optimista asociada al crecimiento de la productividad agrícola e industrial y su aporte en el control del hambre y en la mejora de los déficits nutricionales llevó a una redefinición de lo alimentario, a una mayor atención científica hacia su calidad y a una nueva preocupación por el acceso a ellos en momentos de crisis o por grupos específicos, como el de los niños (Stearns, 2012). En este escenario, el fraude alimentario también adquirió visibilidad, como ha mostrado Atkins (2013, p. 100) para el caso europeo, ya no solo como resultado de los cambios en los procesos industriales, sino principalmente por el surgimiento de una estructura fiscalizadora, apoyada en la química, que ubicó al análisis como principal método de control.

Desde esta perspectiva, este artículo revisa y analiza, como un primer avance de investigación, la entrada del acervo científico en la fiscalización del fraude alimentario durante el primer decenio de funcionamiento del Instituto de Higiene. Entendiendo el fraude como una acción engañosa basada en la sustitución o adición intencional de alguna sustancia en un producto determinado, con el objeto de aumentar su valor o reducir los costos de producción buscando una ganancia económica (Rioux, 2018; Atkins, 2013), este estudio se centra en las nuevas dinámicas de control de alimentos y específicamente en la malla estatal-científica que colaboró en su identificación y en la evaluación de sus riesgos. Para esto, presenta las normativas que rodearon a los alimentos, reflexiona en torno a las nuevas comunidades científicas que comenzaron a formarse para gestionar estos problemas, y plantea que estas, pese a las dificultades que enfrentaron para articularse entre sí, cumplieron un rol protagónico en la confección de una red de control y en la definición de nuevos estándares de calidad y de transgresión. Finalmente, aborda la relación de este sistema de control con la judicialización de los riesgos alimentarios y la entrada a tribunales de nuevos recursos provenientes del mundo de la higiene y de la química.

Scholliers (2014, p. 547) plantea que el surgimiento del laboratorio mu- 
nicipal respondió a aspectos económicos relacionados con la competencia y la demanda, el desarrollo profesional de sus actores, las relaciones de poder entre gobiernos locales y nacionales, así como el aporte científico en el control de la salud pública, entre otras razones. Estas características son las que hacen al laboratorio una institución interesante de estudiar, a través de fuentes estatales como el Diario Oficial, publicaciones periódicas de la Sociedad de Farmacia, del Instituto de Higiene y de las municipalidades, por medio de la prensa y de los registros judiciales, con el objetivo de indagar en los debates que suscitaron los alimentos, y en las estrategias de control sanitario, revisando su alcance y las respuestas entregadas por los grupos que participaron de estos cambios. En una primera parte, el artículo presenta la preocupación generada por problemas en los alimentos y las normativas generales circunscritas al campo de la higiene. En la segunda y la tercera parte, se exploran esfuerzos específicos, que dan cuenta de las tensiones relacionadas con el ejercicio de la fiscalización y el análisis, y el peso del recurso científico en la justicia.

\section{LA PREOCUPACIÓN POR LOS ALIMENTOS: REGULAR EL RIESGO}

Si bien hay coincidencia en que el progreso trajo consigo una serie de mejoras asociadas con la diversificación de los alimentos y la disponibilidad de una mayor gama de productos, también hay acuerdo en que este provocó tensiones que derivaron en nuevos modos de intervención social y de gestión del bienestar. La historiografía ha dado cuenta de la relación entre la temprana modernidad y la circulación de productos alimenticios deficientes o adulterados (Guillem-Llobat, 2009; Atkins, 2013). Los numerosos cambios en las formas de producción, conservación y circulación de bienes complejizaron la cadena alimenticia, distanciaron a productores y consumidores e introdujeron presiones a un mercado cada vez más competitivo que generó brechas y fisuras que afectaron la calidad e identidad de alimentos y bebidas (Ravasz et al., 2012).

Chile no estuvo ajeno a estos problemas. Los delitos por los que se castigaba a Luciano, Rosario, Antonio y Moisés en San Felipe tenían relación con estos cambios. Pese a no ser nuevas, estas infracciones habían adquirido gran protagonismo en el cambio de siglo por el despunte industrial y científico. En primer lugar, el desarrollo preliminar de la producción alimenticia -por su condición de bien primario, su relación con los recursos naturales disponibles y la baja especialización inicial que requería- ayudó al surgimiento de nuevas industrias agroalimentarias, precursoras de una 
producción masiva y seriada, y también de pequeños talleres semi-industriales que elaboraban harina, aceite, licores, galletas, embutidos y cervezas, entre otros. A esto se sumó el incremento de artículos extranjeros, algunos nuevos -como la margarina o la leche condensada-, que ayudaron a diversificar el mercado y activar la competencia (Valenzuela y Contreras, 2013; Robles, 2009, 2018 y 2020; Couyoumdjian, 2006; Martínez, 1896 y Espech, 1887). Esto generó estrategias comerciales que en pos del provecho sacrificaron la calidad y la sanidad de alimentos y bebidas, problema que ha sido estudiado en Chile particularmente para la industria de los vinos y alcoholes (M. Fernández, 2010). Adicionalmente, los nuevos procesos productivos desacreditaron antiguos procedimientos, mientras que las demoras o problemas en la activación de nuevas tecnologías generaron sospechas respecto a la calidad de los productos derivados de sistemas más modernos.

La migración campo-ciudad, sumada a las condiciones de vida de gran parte de la población urbana hacinada en ranchos y conventillos, añadió a los riesgos señalados problemas de higiene anclados a consumos descuidados, que gran parte de las veces se realizaban en la vía pública, sea en mercados, cocinerías o baratillos, en condiciones cuestionables de sanidad (Palma, 2004, p. 401). Esto se volvía más problemático en un mercado en el que se estaban negociando y redefiniendo los elementos formales capaces de garantizar ingredientes y calidades, tanto de los productos a granel, como de las manufacturas alimenticias que sujetas a las leyes de marcas y patentes, comenzaban a abundar en la capital.

Estas preocupaciones no pasaron inadvertidas. El desarrollo de la higiene -en tanto paradigma híbrido que sumaba a la tradición hipocrática y miasmática la síntesis sanitaria-bacteriológica que comenzaba a gestarse hacia fin de siglo- había ayudado a visibilizar y legitimar los numerosos problemas de salubridad que se vivían en las ciudades y a levantar nuevos diagnósticos que serían fundamentales para diversas acciones sanitarias pensadas para el ámbito hídrico, hospitalario, habitacional o terapéutico, entre otros (Hidalgo, 2002; Folchi, 2007; E. Fernández, 2015; Bassa y Fuster, 2013; Booth, 2013, Simón y Sánchez, 2017). La higiene, como paradigma decimonónico por esencia, se preocupó de las causas sociales, ambientales y morales que afectaban la salud de la población y del país, apoyándose en recursos como la estadística y en disciplinas como la medicina y la química (Velmet, 2020).

En este contexto, fueron los farmacéuticos y médicos, particularmente aquellos interesados en la higiene, los que avistaron la cuestión alimentaria. Los farmacéuticos reunidos en torno a la Sociedad de Farmacia, creada en 
1858, advirtieron sobre las precauciones que se debían tomar en el nuevo contexto industrial, particularmente por la existencia de sustancias, como colorantes y metales galvanizados, que interactuaban con los comestibles y los volvían insalubres (Correa, 2020). Su diagnóstico advertía que hasta las sustancias más inofensivas generaban desórdenes y transformaban el potencial nutritivo de los alimentos en algo riesgoso. Los médicos, una comunidad más numerosa en los ámbitos de gobierno, profundizaron en las implicancias que la adulteración alimentaria tenía en la salud, vinculándola con enfermedades y accidentes como cuadros de tifus y envenenamientos, así como con los llamados desórdenes sociales como el crimen y la corrupción. Los alimentos constituían para estos profesionales un recurso clave para la población, en tanto eran la base que permitía "colocar a los individuos en condiciones de resistencia" frente a la vida (Del Río, 1901). Sus diagnósticos se apoyaban además en los desarrollos recientes de la bacteriología y la nutrición, lo que contribuyó a ubicarlos como agentes relevantes en el control de la higiene alimentaria y en el desarrollo de políticas de acceso a la alimentación (Deichler, 2016; Yáñez 2017 y 2018).

Los industriales agrupados en la Sociedad de Fomento Fabril (creada en 1883), interesados en potenciar la industria nacional y defender sus intereses, también se ocuparon de los fraudes y los vincularon con el desarrollo de un mercado global de alimentos, poco regulado, que permitió la circulación de productos adulterados chilenos y extranjeros que aumentaban el lucro a costa de la calidad. El afán de enriquecimiento incitaba prácticas identificadas como maliciosas y punibles que erosionaban la confianza y afectaban la salud. Su diagnóstico complementaba una apreciación más general que postulaba que esta situación no solo oscurecía las calidades y suponía nuevos peligros sanitarios, sino que además cambiaba las reglas del juego del mercado y afectaba los negocios de la industria nacional (Subercaseaux, 2002).

Pero no solo los colectivos científicos o empresariales advirtieron sobre este problema. La prensa alertó sobre los riesgos alimentarios e informó frecuentemente sobre accidentes y crímenes asociados a ellos. La viñeta publicada por Zig-Zag ya iniciado el siglo XX, titulada "Artículos que se consumen en Santiago" (Fig. 1), ironizaba sobre la verdadera identidad de los productos que circulaban en la capital: charqui de vaca fabricado a partir de un caballo viejo y esquelético, leche de vaca holandesa elaborada en una "lechería modelo" que se extraía directamente de un grifo, al igual que el vino, en alusión a la agregación de agua, tan extendida en el país. También 
se recomendaba un "riquísimo" queso "muy digestivo", hecho de adobe, y las salchichas de chancho producidas con perros callejeros (Zig-Zag, 12 de mayo de 1907). En "Santiago, la ciudad de la mugre" (Fig. 2), el panorama no era más alentador. Agobiada por problemas sanitarios, los tarros de basura eran presentados, por medio de una cita darwinista, como recurso base para "la lucha de la existencia" y los centros de abastos como cuna de una colonia de microbios (Zig-Zag, 11 de agosto de 1907).

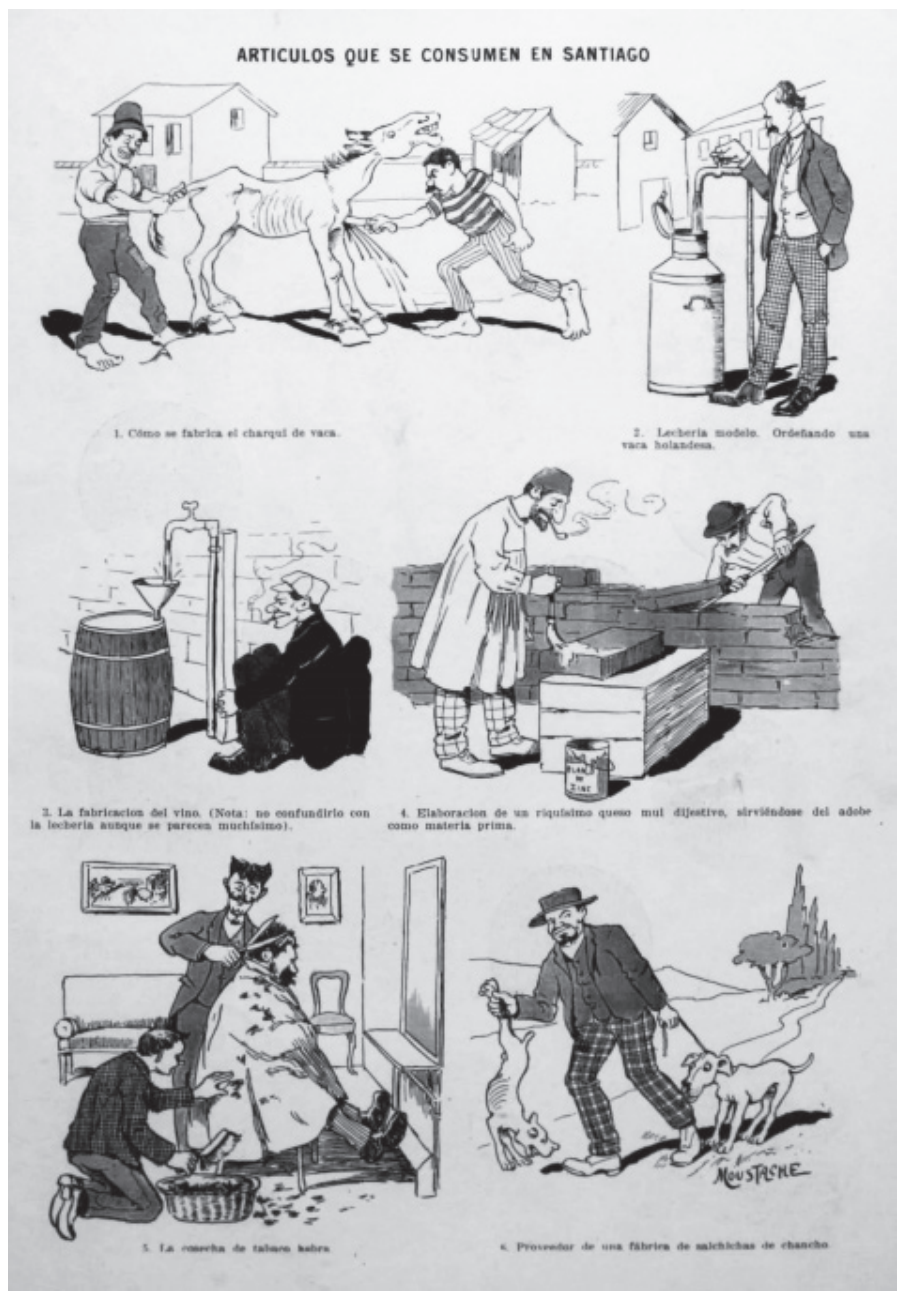

Figura 1. Artículos que se consumen en Santiago, Zig-Zag, 12 de mayo de 1907, s.p. 


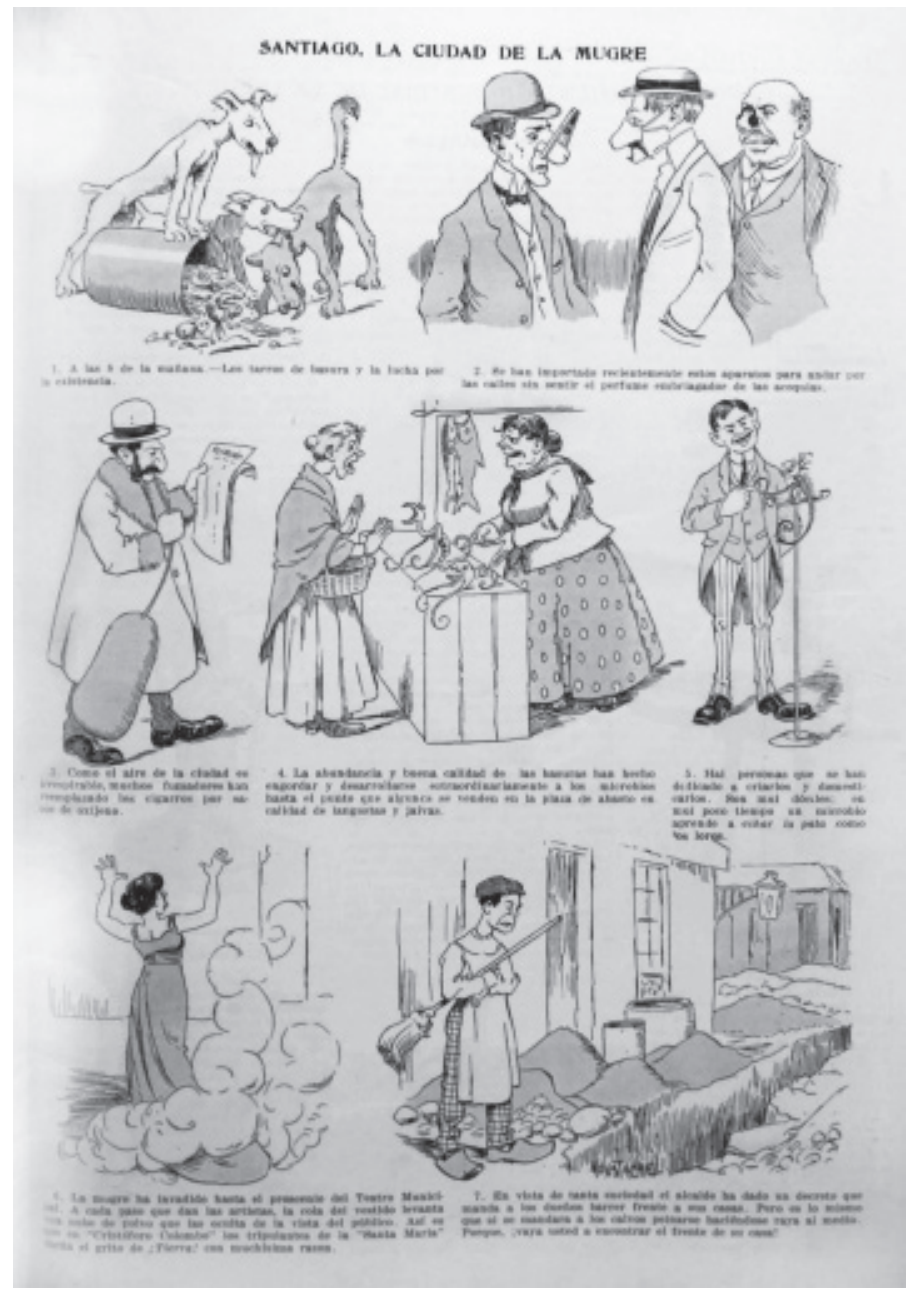

Figura 2. Santiago, la ciudad de la mugre, Zig-Zag, 11 de agosto de 1907, s.p.

En este contexto y en los últimos decenios del XIX, la vigilancia sobre los bienes de consumo se acrecentó. En 1874 el Código Penal castigó la circulación de objetos dañosos, agrupando normativas que no eran del todo desconocidas. Productores, dueños de fondas, cafés o confiterías, entre otros, serían penalizados si elaboraban o vendían sustancias alimenticias nocivas para la salud, con reclusión menor, multas entre 100 y 500 pesos o destrucción de los objetos. Esto afectaba especialmente a quienes alteraban "con cualquier mezcla nociva a la salud" las bebidas o comestibles destina- 
dos al consumo público, a quienes comercializaban o compraban bienes "destinados a ser inutilizados" y al que arrojaba "en fuente, cisterna o curso de agua destinada a la bebida, algún objeto que la haga nociva para la salud" (Código Penal, 1889, pp. 116 y 117). También decomisaba los "efectos falsificados, adulterados o averiados que se espendieran como lejítimos o buenos", así como "los comestibles en que se defraudare al público en cantidad o calidad" (Código Penal, 1889, p. 179).

Las crisis sanitarias, como aquellas originadas por los contextos epidémicos, fueron funcionales a la conformación de normativas más precisas, agenciadas por una estructura higiénica que poco a poco fue reemplazando la gestión del Protomedicato, otrora con funciones de policía sanitaria, judicial y examinadora (Molina, 2010). Con la epidemia de viruela se creó el Consejo de Hijiene y Salubridad Pública (1872), y tras una década el cólera impulsó la Ley de Policía Sanitaria (1886), la Ordenanza Jeneral de Salubridad, la Junta General de Salubridad y las Juntas Departamentales de Salubridad (Illanes, 2007, p. 48 y Ordenanza General de Salubridad, 1887). Estas instancias reforzaron la condena a "las bebidas, confites y alimentos mal sanos" y recordaron el deber de los directivos de dictar las reglas o disposiciones para el buen expendio de licores, bebidas y materias alimenticias (Vicuña Mackenna, 1878, p. 169; Villanueva y Killing, 1887, p. 6). Se prohibió la venta de frutas, pescado, carne y todo artículo de consumo, "que por encontrarse en mal estado" afectase la salud, así como se condenó "la venta de licores i bebidas dañosas como aguardientes de granos no rectificados, licores torcidos o bebidas alteradas con mezclas nocivas". Un cuidado similar se buscó ejercer sobre el agua, al prohibirse el baño y el lavado en las acequias que surtían de agua potable, como también arrojar en ellas "basuras, aguas sucias, barros, lavazas o cualquiera otra sustancia o desperdicio" (Ordenanza Jeneral de Salubridad, 1887, p. 7). Posteriormente la Ley de Organización y Atribuciones de las Municipalidades, promulgada en 1891, definió las facultades y deberes higiénicos del municipio. Un año después, la creación del Instituto de Higiene gestó una nueva institucionalidad, destinada a tener un rol protagónico en el cuidado de la higiene, y asociada a ella, de los alimentos. Esta impulsó, no sin conflictos, una política de control de alimentos que tuvo como socia a la municipalidad, y como aliada a la justicia, y que fue fundamental no solo para el manejo del delito de fraude, sino para la conformación de regulaciones más específicas sobre las características de ciertos alimentos y sus formas de calificación. En este proceso la municipalidad, en tanto menor unidad política-administrativa del Estado, estuvo muy presente. Si bien había gestionado desde 
su creación diversas tareas de orden sanitario, manteniendo algunas funciones del cabildo relacionadas con el aseo y la policía, las leyes orgánicas de 1854 y 1887, y luego, la de 1891, reforzaron su rol en la fiscalización de los alimentos (Rengifo, 2020, p. 254). Esta última normativa determinó que correspondía al municipio conocer "de todo cuanto se refiere a la higiene pública i estado sanitario de las localidades", como permitir y fijar las reglas de mercados y mataderos, vigilar el expendio de carne, pescado, marisco, fruta, leche, licores y bebidas, y cualquier sustancia alimenticia que pudiese ser nociva para la salud; establecer inspectores que vigilasen la venta de productos en buen estado, revisar la limpieza de las vasijas y materiales empleados por confiterías, cafés y fondas, así como examinar las fábricas e industrias y la sanidad de sus procesos productivos (Ley de Comuna Autónoma, 1891, p. 271).

La preocupación por la higiene modificó la institucionalidad sanitaria y sumó nuevas formas de control. Surgió así un cuerpo normativo que, poco a poco, fue creciendo en sustrato y complejidad ${ }^{1}$. Esta incluyó diversas instituciones y actores y desplegó una extensa red de vigilancia en las distintas ciudades del país. Si bien no es posible aún conocer el impacto de estas políticas en la calidad de los productos en circulación y en el control de la falsificación, esta presencia colaboró en la validación de nuevos modos de fiscalización sanitaria y de identificación del fraude que fueron centrales para su judicialización. Con ellas surgieron nuevos expertos, capaces de implementar las políticas de inspección e interpretación de los alimentos, cuya presencia no respondió solo a las posibilidades laborales que se gestaron con el crecimiento del Estado y el ordenamiento de sus empleados a través de la burocratización, sino también al reconocimiento de su potencial aporte como resultado de competencias formativas o experiencias prácticas específicas (Barría, 2015 y 2018).

Si en un primer momento el foco de atención estuvo puesto sobre los abastos públicos, entendidos también como una importante fuente de ingresos para las municipalidades, con el tiempo y con la presencia de nuevas tecnologías, técnicas y expertos, la normativa abarcó aspectos más definidos de los alimentos relacionados con los porcentajes de azúcar, la regulación de ácidos, sales y colorantes, y el empleo de determinados envases,

\footnotetext{
${ }^{1}$ Las normas vinculadas a la industria nacional y extranjera como las de propiedad industrial, marcas de fábrica y privilegios de invención o de importación, también tuvieron un trasfondo sanitario. La "Ley de Marcas de Fábrica" del 12 de noviembre de 1874 correspondió a una iniciativa promovida por la Sociedad Nacional de Agricultura que tuvo entre sus objetivos normar la manufactura y prevenir la falsificación.
} 
poniendo atención a ciertos productos como leche, carne, grasa y alcoholes, entre otros. Para que la aplicación de estas medidas fuese posible se requirió de la creación de una estructura de vigilancia y análisis como la del laboratorio, preparada para identificar, estudiar e interpretar los alimentos, así como de una instancia capaz de hacer uso de sus resultados, como la ofrecida por la justicia.

\section{EL INSTITUTO DE HIGIENE, LA OFICINA DE INSPECCIÓN Y EL LABORATORIO}

La implementación de un sistema de vigilancia e interpretación alimentaria requirió de expertos que pudiesen pesquisar el fraude y activar las normativas. El Instituto de Higiene tuvo la responsabilidad inicial de activar este control sanitario alimenticio, como representante nacional de la higiene, cuna de los principales laboratorios del país y espacio laboral y a la vez formativo de químicos y farmacéuticos con experiencia en la realización de ensayos. Estos últimos tuvieron a su cargo los laboratorios, particularmente el de química y luego el de bacteriología, y a través de ellos se encargaron de los análisis de los alimentos. La municipalidad, en paralelo, nombró inspectores de carnes y de líquidos destinados a encontrar en el mercado los productos fraudulentos y conducirlos al Instituto. Sin embargo, durante los primeros cuatro años de creación del establecimiento, esta alianza no funcionó bien, por el reducido número de muestras que llegaban al Instituto y la desconfianza hacia la capacidad fiscalizadora de los inspectores. Además, hay que agregar que faltaban reglamentos que establecieran tareas y responsabilidades, lo que llevó, por ejemplo, a que durante los primeros años de funcionamiento del Instituto sus empleados salieran a la calle a "inspeccionar en el comercio la calidad de los artículos de interés para la salubridad" (Puga Borne, 1896, p. 31), rivalizando con la responsabilidad de control sanitario municipal.

La creación de la Oficina de Inspección de Líquidos y Sustancias Alimenticias en 1896 por parte de la Municipalidad de Santiago supuso un esfuerzo por mejorar el sistema, y responder de mejor modo al problema del fraude, el que se hacía cada vez más evidente. La comprobación que la sección de Química del Instituto había hecho durante sus primeros años de funcionamiento sobre la frecuencia con que se vendían al público "bebidas y sustancias alimenticias adulteradas o falsificadas" y la necesidad de mejorar la gestión de los inspectores municipales y su relación con el Instituto, 
impulsaron esta iniciativa (Diario Oficial, 17 de octubre de 1896, p. 3). En este sentido, la Oficina, si bien era de carácter municipal, se pensaba como una aliada, destinada a tomar muestras en el espacio público y a llevarlas al Instituto para su análisis, y así, vincular de mejor modo "el odioso papel de los inspectores municipales" con "el abrumador y delicado trabajo de los laboratorios del Instituto" (Diario Oficial, 31 de marzo de 1897, p. 5).

En este marco, la creación de la Oficina representaba un acto prometedor. Se desplegaba como reparadora de una higiene alimentaria que se encontraba en estado crítico, y que como señalaba el inspector sanitario jefe de la Oficina, Julio Gutiérrez, se ubicaba en un momento en que ya casi no se podía consumir alimentos, como leche, vino o chicha, que no estuviesen alterados, o, en sus palabras, que no hubiesen "sido bautizados con la mano zurda" (Gutiérrez, J., 1897, p. 9). Las sustancias alimenticias, tales como el café, el té, el chocolate, la grasa, el queso y la mantequilla, entre otras, pasaban con frecuencia "por manos impuras" (p. 9) que debían ser castigadas. Los análisis practicados durante ese año demostraron la extensión del problema, dando cuenta de que alrededor del $80 \%$ de la leche vendida en la ciudad no cumplía con las exigencias elementales de la higiene, algo que también ocurría con los alcoholes y la chicha (Boletín de Hijiene y Demografía, 1898, p. 32). Este resultado, si bien confirmaba una intuición generalizada, no logó detener dos problemas que llevaron a la desaparición de la Oficina a menos de un año de su creación: las escasas garantías de "competencia y honorabilidad" que las autoridades del Instituto atribuían a los inspectores, y la falta de recursos del Instituto para gestionar la avalancha de muestras enviadas por la Oficina.

Los inspectores de la Oficina representaron para los higienistas un primer problema. Con trayectorias disímiles, algunas de ellas discontinuas, conformaban un equipo diverso que, en palabras del doctor José Joaquín Aguirre, secretario del Instituto de Higiene, no tenían las cualidades para desempeñar "el delicado puesto de inspector", aludiendo a competencias inadecuadas y falta de honorabilidad. Si bien algunos de los diez inspectores activos a inicios de 1897 tenían experiencia formativa o práctica en química -por ser profesores, estudiantes de medicina, agrónomos, propietarios e industriales- no todos contaban con una formación oficial y completa ${ }^{2}$. Tam-

\footnotetext{
${ }^{2}$ Los inspectores de la Oficina fueron: Julio Figueroa, agrónomo; Samuel Merino, licenciado en Medicina: Rafael Toro, estudiante de Medicina; Nicomedes Magnan, profesor de humanidades; Julio Menadier, agrónomo, Waldo Castro, estudiante de Medicina; Carlos Dinator, industrial; Avelino Pacheco, propietario e industrial; Manuel Molina, industrial; Juan Torres, estudiante de Medicina (Diario Oficial, 31 de marzo de 1897, p. 6).
} 
bién faltaban procesos. En varias oportunidades se insistió, por ejemplo, en que los inspectores debían esperar a recibir las instrucciones del Director del Instituto de Higiene sobre la toma y la conservación de las muestras, a fin de que el análisis tuviera las condiciones de exactitud requeridas. Sin embargo, a juicio de los higienistas, "los mugrientos papeles" que acompañaban a las botellas y muestras, y la ignorancia respecto a ciertos productos, corrompían y afectaban su labor (Diario Oficial, 31 de marzo de 1897, p. 6). Las muestras llegaban al Instituto después de pasar por más de cinco o seis personas, lo que problematizaba su capacidad de servir de base en un proceso criminal. Además, algunos inspectores casi no recibían sueldo, lo que levantaba una serie de sospechas respecto a los posibles beneficios que conseguían durante su gestión. Evidentemente que estas críticas se forjaban en un contexto de competencia entre diversos tipos de expertos y de instancias estatales que impactaron, entre otros factores, en el desarrollo de esta nueva política.

La cantidad de muestras constituyó un segundo problema. Durante los casi seis meses de funcionamiento de la Oficina una decena de inspectores envió al Instituto de Higiene un total de 716 ejemplares para análisis -de vino, chica y leche, grasa y chacolí, entre otros-, número que contrastó marcadamente con las 196 muestras remitidas por los inspectores de líquidos entre 1893 y 1896 (Gutiérrez, 1897, p. 14). En este sentido, la creación de la Oficina dio inicio a una nueva fase de fiscalización, mucho más intensiva, que generó una avalancha de muestras que el Instituto no pudo gestionar, y por tanto la justicia tampoco pudo judicializar. Como las autoridades explicaban, durante los meses de funcionamiento de la oficina quedaron rezagadas en el Instituto alrededor del 75\% de las muestras. En este escenario el plantel dejó de analizar los envíos despachados por los inspectores, a la espera de normar mejor su práctica, aumentar la subvención y elevar el número de ensayadores y químicos en sus laboratorios. En el intertanto el Municipio de Santiago cerró la Oficina de Inspección a fines de 1896 por no dar respuestas a las necesidades para las que había sido creada.

En la base de estos problemas estaba la reciente creación del Instituto y el mayor control que las municipalidades habían adquirido sobre la fiscalización de los alimentos. Ciertamente, como se debatía en el Congreso, durante el periodo en que se comenzó a pensar el Instituto y a impulsar sus leyes, Ramón Barros Luco, presidente de la Cámara de Diputados reconocía que el Estado se encontraba en una completa anarquía en estas materias, pues para hacer cualquier ensayo "no se sabe a quién recurrir. No hay quién haga un ensaye de los alcoholes que se espenden al público, ni de las aguas 
potables, ni de las sustancias alimenticias" (Revista Chilena de Hijiene, 1894, núm. 1, p. 114). Esto afectaba especialmente, como enfatizará Barros Luco, a las investigaciones criminales, dado que "las autoridades no pueden disponer de un elemento tan importante de investigación, como es el de los análisis" (Revista Chilena de Hijiene, 1894, núm. 1, p. 114). Adicionalmente, además de la juventud del Instituto se sumaba cierta tensión entre este organismo y la municipalidad, es decir, entre, un actor metropolitano de la higiene y un actor sanitario local. Este roce tenía antecedentes ya en el periodo de creación del Instituto cuando se reconoció que, si bien era cierto que las municipalidades tenían facultades para gestionar la salubridad y la higiene de las poblaciones, también era cierto que "por más buena voluntad que tengan sus miembros y los vecinos (...), no pueden hacerlo, tanto por carecer de competencia para resolver estas materias, como también por no contar con los recursos suficientes" (Revista Chilena de Hijiene, 1894, núm.1, p. 110). Con estas dos características basales, el proyecto de fiscalización alimentaria avanzaría a una nueva etapa.

Ante el fracaso de la iniciativa, surgió la idea de crear un laboratorio en Santiago, como los ya formados en Valparaíso, Antofagasta e Iquique en respuesta al escaso alcance de las labores del Instituto en provincia. Estos recintos eran de carácter municipal y a diferencia de la Oficina de Inspección de Santiago, reunieron en el mismo sitio a inspectores y químicos, pues fiscalizaban y al mismo tiempo analizaban. Buscaban velar localmente por la salubridad pública, cuidar que no se defraudara a los consumidores con alimentos y bebidas nocivas o deterioradas y contribuir como espacio experto en la identificación de las prácticas fraudulentas (Boletín de Hijiene y Demografía, núm. 3, 1898, p. 44). A su cabeza estaban los químicos, graduados de Farmacia en la Universidad de Chile y formados en química orgánica y toxicología, o, en su ausencia, prácticos con experiencia en análisis en aduanas, laboratorios escolares o industrias. Ellos fueron quienes estudiaron las muestras tomadas por los inspectores, apoyados en algunas oportunidades por veterinarios o médicos, que colaboraron tangencialmente en la interpretación del delito.

Estas ideas seguían un proceso global, que había comenzado a manifestarse en Europa a mediados del siglo XIX con la creación de los primeros laboratorios municipales en Bruselas en 1856 y en Paris en 1876, y con la profundización de la iniciativa municipal en el control sanitario y científico, a través de la selección y estudio de la muestra (Scholliers, 2014). En Chile el Laboratorio Químico Municipal de Santiago se creó en febrero de 1898 y en el último patio de la Casa Consistorial, con la perspectiva de reducir 
la sobredemanda del Instituto, mejorar la relación entre los inspectores y los químicos, reforzar la autoridad municipal sobre la higiene alimentaria y contribuir mediante la ciencia a la reducción del fraude.

Los laboratorios se constituyeron como unidades municipales que reunieron bajo su autoridad a inspectores y químicos, y que también funcionaron -especialmente aquellos creados fuera de Santiago- como una proyección del Instituto, al reclutar a varios de los expertos que habían pasado por él. Contribuyeron a la conformación de reglamentos específicos que tomaron la forma de ordenanzas municipales, las que profundizaron la mirada hacia los alimentos y hacia su calidad. Estas determinaron las condiciones de elaboración de ciertos productos, como la leche, abarcando la supervisión tanto de las lecherías, como de los depósitos, envases y derivados. Junto con ello, establecieron la acidez de las chichas y vinos, las características de los ácidos grasos, la venta de sebo como alimento, la composición de los vinagres, los utensilios que entraban en contacto con los alimentos, las cajas de conservas, la aplicación de aditivos y el uso de colorantes, entre otros (Briones, 1902, p. 19).

La creación del Instituto supuso un cambio epistemológico en la forma de considerar los problemas higiénicos, al instalar al experto químico y al análisis como recursos básicos para el control de la alimentación, y como elementos fundamentales del ejercicio de la justicia. La posterior creación de laboratorios municipales junto con validar el espacio de análisis, reforzó la autoridad municipal no solo en la identificación de la sospecha, sino también en el proceso probatorio del delito de fraude a partir del ejercicio científico.

\section{EL MUNICIPIO, EL LABORATORIO Y LA JUSTICIA: PROBAR EL FRAUDE}

Los litigios que involucraron a comerciantes de la ciudad de San Felipe durante la primera década del siglo XX presentados al inicio de este texto, muestran algunas características de los nuevos procesos de gestión del fraude alimentario que pusieron a funcionarios municipales, a la ciencia, y en particular a la química, como actores centrales de la identificación y conceptualización de este delito.

Luciano Rector, Rosario Ríos, Antonio Ramírez y Moisés Zamora, acusados de comercializar alimentos adulterados, pertenecían al heterogéneo grupo de comerciantes que transitaba entre las dinámicas de la agricultura 
latifundaria tradicional y las transformaciones que ofrecían los "bolsones de modernidad" que surgían en el valle central, como los denominó Bengoa (1990, p. 72). El departamento de San Felipe, cercano a Santiago y a orillas del río Aconcagua, había enfrentado en el último tiempo, al igual que otros sectores del país, una mayor subdivisión de la tierra, una progresiva especialización de la agricultura, la modificación gradual de las relaciones de trabajo y cambios significativos en los procesos productivos y comerciales (Bengoa, 1990, pp. 72 y 76; Robles, 2020). Además, acogía a una floreciente industria que consideraba la fabricación de jarcias y cordeles, correas de suela, almidón y licores, entre otros (Prado, 1905, p. 51). En la ciudad eran varios los que se dedicaban a la venta de alimentos y bebidas. Para 1904 el Anuario Pardo identificaba alrededor de 39 bodegas de vinos y licores de las cuales 27 pertenecían a hombres y 12 a mujeres. Posiblemente el número era bastante más elevado, considerando que de los cuatro comerciantes que presentamos, solo Luciano Rector aparece mencionado en el Anuario (Pardo, 1905, p. 52). Probablemente sus tiendas, situadas en los alrededores de la principal arteria de la ciudad, la calle Arturo Prat, se inscribían dentro del comercio de menor cuantía, el que, si bien era parte del escrutinio sanitario, no quedaba del todo reflejado en la estadística comercial del periodo.

Las visitas de los inspectores, la toma de muestras y su posterior estudio, permitieron presentar las acciones comerciales de los comerciantes como ilegales e iniciar procesos probatorios del carácter fraudulento de algunos de sus productos. Las denuncias realizadas por las autoridades se fundaban en los informes entregados por los inspectores y en los resultados arrojados por los análisis realizados en el laboratorio químico de la ciudad. En consecuencia, las acciones del laboratorio activaban la justicia y se proyectaban directamente en los litigios a través de las pericias, en tanto respondían no solo a envenenamientos o accidentes derivados del consumo, sino más bien de la fiscalización directa que ejercía la municipalidad sobre el comercio como parte de sus acciones profilácticas.

El proceso iniciado contra Rosario Ríos se sostenía en los resultados obtenidos del análisis de una muestra de vino tinto -la muestra 20- tomada por el inspector municipal en su "casa negocio", la que fue calificada como adulterada. El expediente incorporaba los dos documentos referidos a estos procesos: el acta de la toma de muestra y el boletín de análisis, los que se instalaron como contenidos iniciales y probatorios. El primero avalaba la toma de la muestra en el negocio de Ríos, ante la presencia de los encargados, siguiendo procedimientos destinados a cautelar el proceso: división de la muestra, colocación en una botella, lacrado y sellado inmediato, forma 
de los presentes y tiempos del proceso; mientras que el segundo presentaba los resultados detallados del análisis obtenido en el laboratorio (Archivo Judicial de San Felipe (AJSF), 1901, C1112, P3). Los otros pleitos enfrentados por los comerciantes de la ciudad de San Felipe siguieron modelos similares.

Rosario Ríos se defendió frente a la justicia desde la brecha que abría la distancia entre la calle y el laboratorio. Cuando el licor fue entregado al empleado municipal, este se encontraba, a su juicio, "en perfectas condiciones", opinión que presentó como compartida por "muchas personas entendidas en la materia" (AJSF, 1901, C1112, P3, s/n). Debía considerarse, añadió, que las demoras en la realización de los análisis deterioraban las muestras, "una botella sin taparse, es claro y evidente que sufra alteración" (AJSF, 1901, C1112, P3, s/n), vinculándose a una narrativa más amplia que llamaba la atención sobre cómo los tiempos de los procesos científicos incidían en la calidad de las pericias judiciales (Correa, 2017). Junto con deslegitimar la capacidad probatoria del laboratorio, acusó que la fiscalización se concentraba solamente en los artículos "al menudeo", mientras que los agricultores que les vendían los productos quedaban libres del análisis. Con esto, junto con desacreditar la prueba, Rosario Ríos recordó las responsabilidades que le competían a aquellos actores que se encontraban más atrás en la cadena alimenticia, especialmente a los productores agrícolas de las tierras aledañas a la ciudad.

Es interesante notar que los comerciantes respondieron a la fiscalización a través de narrativas similares. Como Ríos, los otros comerciantes también cuestionaron el sistema probatorio, aludieron al tiempo excesivo que tomaban los análisis y defendieron el buen estado de sus productos en el punto de venta. También visibilizaron una cadena productiva cada vez más compleja y difícil de pesquisar. "Los vendedores de licor al menudeo somos los únicos denunciados, y mientras tanto los agricultores que nos venden están libres del análisis correspondiente”, añadiría Rosario (AJSF, 1901, C1112, P3, s/n). En este contexto, no era posible para los acusados que "tomemos del brazo al señor Químico y andemos con él de salvo conducto por todos los viñedos de Aconcagua para hacer nuestras compras de chichas, vino y aguardientes" y así resguardar el cumplimiento por parte de los productores de los reglamentos municipales (AJSF, 1901, C1112, P3, s/n).

Los comerciantes se defendieron cuestionando el proceso científico y criticando la excesiva atención que se les prestaba como intermediarios de la cadena de alimentos y bebidas. Sus respuestas se situaron en un momento de posicionamiento de la gestión de los laboratorios, entidades nuevas 
en el panorama fiscalizador nacional, y parecieron responder a la mayor criminalización adscrita a aquellos agentes periféricos, que vendían en sus casas o en espacios más alejados del centro comercial de la ciudad, y que fueron considerados por las autoridades como más susceptibles de intervenir fraudulentamente su inventario en pos de conseguir mayores beneficios económicos.

Ciertamente, la primicia de la fiscalización alimentaria impulsada por los laboratorios municipales permite entender algunos de los cuestionamientos que los acusados hicieron de sus procesos. Esta cargaba con ideas preconcebidas respecto a la inspección alimentaria. Como explicaba el primer director del Laboratorio de Santiago Narciso Briones, quien también estuvo a cargo de la Estación Agronómica y fue profesor de química del Instituto Agrícola, el sistema de inspección en sus inicios "no estaba fundado en ningún dato científico, razón por la cual los jueces rara vez aplicaban multas a las personas sindicadas de expender bebidas o licores adulterados" (Briones, 1902, p.12). A esto se sumaban las sospechas en torno a las figuras del inspector y del químico, oficios conocidos, pero acondicionados a los nuevos reglamentos. En el caso de los químicos, si bien contaban con un respaldo formativo anclado a sus estudios en Farmacia, cargaban con su asociación con la botica y los numerosos prácticos que en ellas se desempeñaban. Además, si bien, desde hacía décadas que frecuentaban los tribunales y colaboraban en diversos asuntos relacionados con sus saberes, la diferencia estaba en que en las décadas anteriores muchos de ellos no contaban con grados profesionales, ni con un vinculo formal con el Estado. Realizaban sus análisis en laboratorios ubicados en sus casas o en establecimientos educacionales, y no tenían un respaldo institucional para el ejercicio de su ciencia. Por esto desde al menos 1860, los farmacéuticos y médicos habían solicitado acciones concretas para mejorar su quehacer como peritos del Estado, que incluían desde salarios a mejores condiciones materiales para el desarrollo de sus tareas. Los mismos expertos que apoyaban a la justicia en la pericia de sustancias tóxicas o adulteradas habían informado a las autoridades sobre la necesidad de que estas labores, que representaban trabajos muy delicados y de mucha responsabilidad, no se confiaran a profesores de liceo o a boticarios, ni siquiera a miembros de una sociedad farmacéutica, sino que a individuos formados en la química y en el arte pericial (Diario Oficial, 4 de febrero de 1885).

Si bien hacia fin de siglo estos requerimientos habían alcanzado algún grado de respuesta por parte del Estado, los problemas seguían presentes, especialmente en provincia, espacios que tendían a concentrar un menor 
número de sitios científicos y de burócratas profesionales. Como parte de la burocracia técnica asociada a la expansión del Estado estos expertos aún requerían numerosos apoyos y recursos para legitimar su quehacer en sus nuevas instalaciones. Como se explicaba desde la Intendencia de Colchagua, hacia 1892, la zona requería de expertos y aparatos científicos, por la dificultad que existía para hacer cumplir la ley respecto a la venta de alcoholes mal rectificados y bebidas adulteradas o nocivas por no existir un empleado que pudiese practicar los análisis de los líquidos (Diario Oficial, 24 de noviembre de 1892, p. 2). Por ello, si bien la llegada del laboratorio municipal y de sus expertos le dio densidad científica a la vigilancia alimentaria, apoyó la gestión de los inspectores, encargados bajo el nuevo orden, de tomar las muestras y dirigirlas a los laboratorios, y posicionó el saber específico manejado por los químicos, estos aún pudieron ser objeto factible de crítica y de revisión, por parte, entre otros, de los acusados.

En San Felipe las muestras fueron enviadas al laboratorio municipal que recientemente se había creado en la ciudad, a cuya cabeza se encontraba Aurelio Zilleruelo, quien reunía una experiencia en diversos frentes de su profesión. Como dueño de algunas farmacias de la zona, como la botica y droguería Esmeralda en Valparaíso ${ }^{3}$, y también de una de las cuatro existentes en Quillota en 1898, tenía experiencia como farmacéutico, y también interés en la ciencia y en su difusión, que lo llevaría un par de años después de su participación en estos procesos, a ser nombrado jefe de la sección de mineralogía del Museo de Historia Natural de Valparaíso (Valparaíso en la Exposición Nacional, 1884 y Diario Oficial, 5 de agosto 1904). Si bien esta multifuncionalidad propia de los expertos del periodo no generó en esta oportunidad críticas directas por parte de los acusados, posiblemente porque se complementaba con varios años de experiencia en el Laboratorio Químico Municipal de Valparaíso (1893), refleja la identidad mixta de los expertos que participaban en la justicia y los problemas que esto pudo haber causado en la apreciación del aporte de la química en el control de los alimentos (Diario de Sesiones, Sesión del 26 de noviembre de 1896).

\section{CONCLUSIONES}

La creación del Instituto de Higiene y el establecimiento de una red de laboratorios destinados a velar por la higiene nacional inauguraron un nuevo

\footnotetext{
${ }^{3}$ Ubicada en Calle San Juan de Dios no $172-174$ y con cinco empleados.
} 
momento en la fiscalización alimentaria que buscaba reducir la responsabilidad asignada a los sentidos -gusto, vista y olfato- en la evaluación de los alimentos, para dar cabida al análisis científico y a sus nuevas formas de registro, que si bien incluían ciertas prácticas organolépticas, se presentaban como instancias novedosas sostenidas en criterios demostrables. Los resultados iniciales de la gestión de estos laboratorios ratificaron su labor, al identificar más de la mitad de los productos en circulación como riesgosos para sus consumidores.

Ciertamente, con el desarrollo industrial la intervención en los productos alimenticios alcanzó mayor complejidad. Nuevos volúmenes, tipos y tecnologías obligaron a complementar las formas de evaluación de los alimentos, con recursos que colaborasen de mejor modo en la detección del fraude. Si bien desconocemos el alcance de estos nuevos recursos probatorios en términos de la penalización lograda, su presencia contribuyó a la identificación de transgresiones y a la conformación de nuevas metodologías y comunidades expertas relacionadas con el control judicial de los alimentos. También contribuyó a la formación de una burocracia experta destinada a responder desde el Estado las demandas científicas.

En este artículo hemos querido hacer una reflexión introductoria al tema, poniendo el acento en un periodo clave del control alimentario, marcado por la profesionalización de saberes y una mayor organización de la salud pública, caracterizado por el surgimiento del Instituto de Higiene y la entrega del control científico de los alimentos a nivel provincial en los laboratorios municipales y sus empleados. Nos ha interesado dejar plasmado que estos procesos fueron complejos, y que en las acciones de control y de aplicación del análisis interactuaron diversos colectivos que negociaron su autoridad sobre los significados e interpretaciones de los alimentos y bebidas. Estos cambios permiten revisar y repensar la creciente intervención estatal en materia de salud pública desde ángulos vinculados no solo con un plan sanitario nacional, sino con necesidades más locales.

Si bien el fraude alimentario fue un asunto relevante, que en los últimos años del siglo XIX e inicios del XX mostró un mayor reconocimiento en la estadística estatal, la acción de los laboratorios a través del municipio, de sus inspectores y químicos, permite proyectar su gestión más allá del plan maestro asociado al Instituto de Higiene como rector de la higiene pública del país. El reconocimiento de la nueva calidad adscrita a los inspectores y de la especificidad de los químicos, se ancló a las realidades económicas, industriales, comerciales y sanitarias de cada municipio y de cada provincia. Sus figuras y acciones aportan a la comprensión del ejercicio cotidiano y 
subjetivo de la justicia, la introducción y uso de los recursos científicos, así como también a los procesos de elaboración y definición de los alimentos modernos.

Las formas de control del fraude por medio de los laboratorios municipales, como el de San Felipe, activaron nuevas dinámicas de fiscalización basadas en la alianza entre la justicia, el municipio y el laboratorio, que permitieron que este último no solo participara en la comprobación del delito, sino que recogiera interesantes suministros para la construcción de definiciones alimentarias y de normas $\mathrm{u}$ ordenanzas relacionadas con los componentes de los alimentos y con sus realidades específicas. Estas tareas incorporaron los avances desarrollados por la química orgánica durante el siglo XIX, y permitieron describir variaciones en las composiciones de los alimentos y bebidas y grados de adulteración, lo que los transformó en interesantes sitios de ciencia, estrechamente cruzados por los intereses municipales y comerciales, mostrando una ciencia y, por consiguiente, una actividad pericial, que no se dedicó a describir la realidad, sino más bien a crear nuevas realidades, vinculadas con las características de los mercados y contextos en los que se desenvolvía.

\section{REFERENCIAS}

Archivo Histórico Nacional (1901). Archivo Judicial de San Felipe, Laboratorio Químico, Caja 770, pieza 7.

Archivo Histórico Nacional (1901). Archivo Judicial de San Felipe, Laboratorio Químico, Caja 770, pieza 8.

Archivo Histórico Nacional (1901). Archivo Judicial de San Felipe, Laboratorio Químico, Caja 770, pieza 9.

Archivo Histórico Nacional (1901). Archivo Judicial de San Felipe, Laboratorio Químico, Caja 774, pieza 9.

Archivo Histórico Nacional (1901). Archivo Judicial de San Felipe, Laboratorio Químico, Caja 1112, pieza 3.

Atkins, P. (2013). Social History of the Science of Food Analysis and the Control of Adulteration. En A. Murcott, W. Belasco, \& P. Jackson (eds.). The Handbook of Food Research (pp. 97-108). Londres: Bloomsbury.

Barría, D. (2015). Empleados públicos y clase media, Chile 1880-1920: un análisis exploratorio a partir de cifras oficiales. Revista de Historia y Geografía, $32,77-100$.

Barría, D. (2018). Carreras administrativas en Chile, 1884-1920 ¿Patronazgo o carreras burocráticas? Historia 51(2), 317-338.

Bassa, J. y Fuster, N. (2013). La medicalización del espacio popular en Santiago de Chile (siglos XIX y XX). Revista Austral de Ciencias Sociales, 24, 5-26. 
Bengoa, J. (1990) Haciendas y campesinos. Historia social de la agricultura chilena, tomo II. Santiago: Ediciones Sur.

Boletín de Hijiene i Demografía 3. (1898). Santiago: Instituto de Hijiene.

Booth, R. (2013). Higiene pública y movilidad urbana en el Santiago de 1900. $A R Q, 85,52-61$.

Boudia, S. \& Jas, N. (2007). Introduction: 'Risk Society' in Historical Perspective. History and Technology 23(4), 317-331.

Briones, N. (1902). Creación del Laboratorio Químico Municipal de Santiago. Revista Farmacéutica Chilena, 1, 11-20.

Código Penal de la República de Chile (1889). Santiago: Imprenta Nacional.

Correa, M.J. (2017). "No siempre (las) tripas llevan pies". Toxicología, análisis científico y condiciones procesales en la justicia chilena, 1877-1907. Revista Historia y Justicia, 8, 69-96.

Correa, M.J. (2020). De la farmacia a la toxicología. La química en tribunales y la conformación de una experticia judicial, Santiago de Chile, 1831-1897. Trashumante. Revista Americana de Historia Social, 15, 59-81.

Couyoumdjian, R. (2006). Vinos en Chile desde la Independencia hasta el fin de la Belle Époque. Historia 39(I), 23-64.

Degreef, F. y Scholliers, P. (2019). Trust in Food in the Modern Period, Food and Foodways 27(1-2), 1-13.

Deichler, C. (2016). Historia y alimentación popular. Dos décadas de lucha médica contra la desnutrición en el Chile urbano, 1930-1950. Santiago: Ministerio de Salud.

Del Río, A. (1901). Lecciones de hijiene pública i privada (apuntes tomados por los alumnos). Santiago: Imprenta de El Consejo de Temperancia.

Diario de Sesiones, Sesión del 26 de noviembre de 1896.

Diario Oficial, 4 de febrero de 1885, 24 de noviembre de 1892, 17 de octubre de 1896, 31 de marzo de 1897, 5 de agosto 1904.

Espech, R. (1887). La industria fabril en Chile: estudio sobre el fomento de la industria nacional presentado al Ministerio de Hacienda. Santiago: Imprenta Victoria.

Fernández, M. (2010). Bebidas alcohólicas en Chile. Una historia económica de su fomento y expansión, 1870-1930. Santiago: DIBAM-UAH.

Fernández, E. (2015). Estudio sobre la génesis y la realización de una estructura urbana: la construcción de la red de alcantarillado de Santiago de Chile. (1887-1910). Historia 48(1), 119-193.

Folchi, M. (2007). La higiene, la salubridad pública y el problema de la vivienda popular en Santiago de chile, 1843-1925). En R. López (coord.). Historia urbana de Latinoaméricas siglos XVII-XX (pp. 361-388). México D.F.: Benemérita Universidad Autónoma de Puebla.

Gajardo, A. (1901). El Laboratorio Municipal de Iquique. Primer Congreso Médico Latino-Americano, tomo I (pp. 323-329). Santiago: Imprenta, Litografia, Ecuadernacion Barcelona.

Guillem-Llobat, X. (2009). De la cuina a la fábrica. L’aliment industrial i el frau. 
El cas valenciá en el context internacional (1850-1936). Alicante: Universitat d'Alacant.

Gutiérrez, B. (2018). Fuentes lexicográfiucas para la historia de la alimentación y del fraude alimentario en la España del siglo XIX. Dynamis 38(1), 87-100.

Gutiérrez, J. (1897). La Oficina de Inspección de Líquidos y Sustancias Alimenticias. Santiago: Imprenta Mejía.

Hidalgo, R. (2002). Higienismo, beneficencia católica y vivienda obrera en Chile a finales del siglo XIX. Estudios Ibero-Americanos 28(1), 51-83.

Illanes, M.A. (2007). Cuerpo y sangre de la política. La construcción histórica de las Visitadoras Sociales (1887-1940). Santiago: Lom.

Ley de Comuna Autónoma (1891). Boletín de Leyes y Decretos LX(12), 271-272.

Martínez, R (1896). Industria Santiaguina. Santiago: Imprenta y Encuadernación Barcelona.

Molina, C. (2010). Institucionalidad sanitaria chilena. 1889-1989. Santiago: Lom.

Ordenanza Jeneral de Salubridad (1887). Santiago: Imprenta Nacional.

Palma, D. (2004). De apetitos y de cañas. El consumo de alimentos y bebidas en Santiago a fines del siglo XIX. Historia, 37, 391-417.

Pardo, A. (1905). Anuario Prado Martínez. Única Guía General de Chile 19041905. Santiago: Centro Editorial de Alberto Prado Martínez.

Puga Borne, F. (1896). Compendio de Medicina Legal adaptado a la legislación chilena. Santiago: Imprenta Cervantes.

Ravasz, E., Toroczkai, M., Lakner, Z., \& Baranyi, J. (2012). Complexity of the International Agro-Food Trade Network and Its Impact on Food Safety. PLoS ONE 7(5), 1-10.

Rengifo, F. (2020). Poder municipal. La territorialización del gobierno estatal en Chile, 1830-1890, Palimpsesto 10(17), 247-266.

Revista Chilena de Hijiene. Santiago: Instituto de Hijiene (1894).

Revista Zig-Zag (1907). Santiago: Zig-Zag.

Rioux, S. (2018). Capitalist food production and the rise of legal adulteration: Regulating food standards in $19^{\text {th }}$-century Britain. Journey of Agrarian Change 19(1), 1-18.

Robles, C. (2009). La producción agropecuaria chilena en la "Era del Salitre" (1880-1930). America Latina en la Historia Económica. Revista de Investigación, 32, 113-136.

Robles, C. (2018). Mechanisation in the Periphery: The Experience of Chilean Agriculture, c. 1850-90. Rural History 29(2), 195-216.

Robles, C. (2020). The agrarian historiography of Chile: foundational interpretations, conventional reiterations, and critical revisionism. Historia Agraria, 81, 93-122.

Scholliers, P. (2014). Constructing New Expertise: Private and Public Initiatives for Safe Food (Brussels in the First Half of the Nineteenth Century). Medical History 58(4), 546-563.

Simón, I. y Sánchez, R. (2017). Introducción del paradigma higiénico sanitario 
en Chile (1870-1925): discursos y prácticas. Anuario de Estudios Americanos 74(2), 643-674.

Stearns, P (2012). Satisfaction not Guarenteed. Dilemas of Progress in Modern Society. New York: New York University Press.

Subercaseaux, B. (2002). Escenificación del tiempo histórico (nacionalismo e integración). Cuadernos de Historia, 22, 185-202.

Valenzuela, L. y Contreras, R. (2013). Industria agroalimentaria y agroindustria hortofrutícola en Chile hasta 1930: antecedentes para una construcción histórica. Historia 396, 2, 351-377.

Valparaíso en la Exposición Nacional de 1884 (1884). Valparaíso: Imprenta del Nuevo Mercurio.

Velmet. A. (2020). Pasteur's Empire. Bacteriology \& Politics in France, its Colonies, \& the World. New York: Oxford University Press.

Vicuña Mackenna, B. (1878). Un año en la Intendencia de Santiago. Santiago: Imprenta de la Librería del Mercurio.

Vieira, R. (2016). Rethinking the History of the Risk Society: Accident Reporting, the Social Order and the London Daily Press, c. 1800-30. En T. Crook \& M. Esbester (eds.). Governing Risks in Modern Britain Danger, Safety and Accidents, c. 1800-2000 (pp. 55-76). London: Palgrave.

Villanueva, A. y Killing, C. (1887). Reglamento de la Junta de Salubridad de Valparaíso e informe presentado por los señores Augusto Villanueava i Carlos Killing relativo a la epidemia del Cólera y algunos medios para la desinfección. Valparaíso: Imprenta del Nuevo Mundo.

Yáñez, J.C. (2017). La comunidad médica y su lucha en contra de la desnutrición en Chile (1860-1940). Revista Médica de Chile 145(8), 1060-1066.

Yáñez, C. (coord.) (2018). Gobernar es alimentar. Discursos, legislación y políticas de alimentación popular, Chile, 1900-1950. Santiago: América en Movimiento. 